\title{
DERECHO, SISTEMA Y REALIDAD: ¿EL POSITIVISMO SE HACE AGUA EN NUESTRAS MANOS?*
}

\section{LAW, SYSTEM AND REALITY: IS POSITIVISM ESCAPING FROM OUR HANDS?}

Andrés Botero-BERNAL ${ }^{* *}$

\section{Resumen:}

El presente escrito buscará explicar las ideas más relevantes y las más controversiales de la tesis doctoral de Ricardo Guibourg, denominada "Derecho, sistema y realidad" (1986). Igualmente, siempre de cara a lo anterior, se expondrán dos aportes adicionales: la importancia de dicho texto en el conjunto del pensamiento iusfilosófico de Guibourg y el contexto de producción intelectual de la iusfilosofía argentina durante el último cuarto del siglo XX.

Se considera que de la debida comprensión de estos tres aspectos (las ideas de la obra, el pensamiento iusfilosófico del autor y su contexto intelectual) surgirá una adecuada y pertinente lectura (más allá del texto mismo) de la tesis "Derecho, sistema y realidad". Esto, porque se cree que una lectura respetuosa, a la vez que crítica, del texto y de su contexto, es fundamental para comprender la crisis ineludible del positivismo vislumbrada, entre otros, por Ricardo Guibourg.

\section{Palabras clave:}

Guibourg, derecho, sistema, realidad, eficacia, positivismo, estructuralismo, funcionalismo.

* Artículo recibido el 19 de noviembre de 2019 y aceptado para su publicación el 29 de abril de 2020. Resultado de investigación financiado con recursos del proyecto 2516 (código SIVIE) de la Universidad Industrial de Santander (Colombia).

** Profesor titular de la Escuela de Filosofía de la Universidad Industrial de Santander (UIS). Correo electrónico: botero39@gmail.com, ORCID: https://orcid. org/0000-0002-2609-0265. 


\title{
ANDRÉS BOTERO BERNAL
}

\begin{abstract}
:
This paper aims to explain the most important and most controversial ideas of Ricardo Guibourg's doctoral thesis, "Derecho, sistema y realidad" (1986). Two additional contributions of Guibourg's thought will also be discussed: first, the importance of his doctoral thesis in his legal philosophy as a whole and second, the context of intellectual production in Argentine legal philosophy during the last quarter of 20th Century.

A proper understanding of these three aspects (the ideas in the work, author's legal philosophy and its intellectual context) will emerge from an appropriate and relevant reading (beyond the text itself) of the dissertation entitled "Derecho, sistema y realidad". This paper is important because it is believed that a respectful and critical reading of the text and its context is key to understand the inevitable crisis of positivism foreseen, among others, by Ricardo Guibourg.
\end{abstract}

\section{Keywords:}

Guibourg, Law, System, Reality, Efficacy, Positivism, Structuralism, Functionalism. 


\section{DERECHO, SISTEMA Y REALIDAD...}

SumARIO: I. Introducción. II. Historia de la tesis doctoral. III. La tesis doctoral de 1986. IV. Proyección de la tesis en la obra posterior de Guibourg. V. Reflexiones finales. VI. Bibliografia citada.

\section{INTRODUCCIÓN}

Si seguimos la concepción tradicional, la tesis doctoral de un reconocido profesor seguro fue su obra más importante (o está entre las más importantes), en tanto que dicha concepción nos ha hecho creer que gracias a ella se le abrieron puertas que dieron lugar a una fructífera carrera académica, de un lado, y que ella marcó un rumbo en una serie de preocupaciones que ocuparán las atenciones del autor por largo rato, del otro. Y esta concepción tradicional se cumple tratándose de la tesis doctoral del profesor bonaerense Ricardo Guibourg [1938-], intitulada "La ciencia bifronte del derecho"1 y publicada el mismo año de su sustentación (1986) con el nombre de "Derecho, sistema y realidad". 2

Con base en lo anterior, ya podemos denotar la importancia prima facie de esa obra en el marco general del pensamiento de su autor. Sin embargo, queremos ir más allá de esta constatación, por lo cual exploraremos en las siguientes páginas el contexto de creación de la tesis, las ideas allí defendidas y la forma como estas impactaron otras obras posteriores de Guibourg. Esperamos, de esta manera, aprovechar la tesis de 1986 para dar algunas luces sobre aspectos más generales y no por ello menos importantes, como el desarrollo de las escuelas positivistas argentinas - que vivieron un momento de esplendor en la segunda mitad del siglo XX y que aún siguen arrojando buenos resultados-, y la producción general iusfilosófica de uno de sus más reconocidos miembros.

Ahora bien, para llegar al cometido antes propuesto, dividiremos este trabajo en los siguientes apartados. El primero estará dedicado

1 Guibourg, Ricardo, La ciencia bifronte del derecho, Tesis Doctor en Derecho, Buenos Aires, Facultad de Derecho de la Universidad de Buenos Aires.

2 Guibourg, Ricardo, Derecho, sistema y realidad, Buenos Aires, Astrea, 1986. 


\section{ANDRÉS BOTERO BERNAL}

a mostrar el contexto de creación de la tesis de 1986. El segundo apartado analizará, con algo más de detalle, las ideas, la metodología y las fuentes de la tesis doctoral. Y el tercero y último se centrará en ver cómo dichas ideas se desarrollaron en obras posteriores del autor, convalidando lo dicho inicialmente: que la tesis doctoral fue una de sus obras más importantes y que marcó el rumbo de muchas reflexiones posteriores.

Valga aclarar que para la elaboración de este escrito nos fundamos en fuentes bibliográficas (de las que se irán dando cuenta a lo largo del trabajo), fuentes personales (fruto de la experiencia del autor de este escrito, quien fue formado doctoralmente al interior de esta tradición iusfilosófica argentina) y fuentes testimoniales (resultado de varias entrevistas con Guibourg, destacándose una del 17 de julio 2018 en Baltimore, EE.UU., que aportaron datos importantes para la elaboración de los dos primeros capítulos del artículo).

\section{HISTORIA DE LA TESIS DOCTORAL}

La idea central de la tesis apareció de manera temprana, por así decirlo, en la mente de Guibourg. Nada más y nada menos que cuando era un joven estudiante de la carrera de abogacía en la Universidad de Buenos Aires (en adelante, UBA), justo cuando con su espíritu crítico hacía sus primeras lecturas del gran filósofo del derecho del siglo XX, Hans Kelsen, ampliamente conocido en los ámbitos académicos argentinos, dado las buenas traducciones que circulaban en Argentina de su obra, el buen conocimiento que muchos profesores del joven Guibourg tenían del austriaco e incluso como resultado de la propia visita que hizo Kelsen a dicho país en $1949 .^{3}$

Más específicamente, la idea de explorar analíticamente las relaciones entre validez y eficacia en la obra de Kelsen le surgió a Guibourg desde el año de 1958, cuando estudió al austriaco, por primera vez, en la asignatura de "Introducción al Derecho". Este interés se vio fortalecido cuando en 1961 estudió, siendo aún estudiante,

3 Sarlo, Oscar, "La gira sudamericana de Hans Kelsen en 1949. El "frente sur" de la teoría pura”, Ambiente jurídico, Manizales, núm. 12, 2010, pp. 401-425. 
otras obras menos conocidas de Kelsen, como la Teoría General del Derecho y del Estado, donde con mayor claridad que en la propia Teoría Pura del Derecho percibió, como si fuese una especie de detective analítico, que algo allí no funcionaba bien: la distinción lógica entre validez y eficacia dejaba abiertos varios agujeros ante los cuales Guibourg acechaba para saber si todo era fruto de una mala lectura o si, por el contrario, dichos agujeros estaban incrustados en el edificio kelseniano. La respuesta estuvo por la segunda vía.

Dicho con otros términos, esta curiosidad detectivesca del joven Guibourg se centró en algunas perplejidades que le generó en torno a la relación que Kelsen hacía entre validez y eficacia, en especial sobre las concesiones que su normativismo le terminaría por hacer al funcionalismo. Justo esta perplejidad fue la que motivó a este estudiante, una vez graduado como abogado, a plantear un proyecto de tesis doctoral en dicha línea, proyecto que le fuera alentado y aprobado por su maestro Ambrosio Gioja [1912-1971], con el título inicial de "La ciencia bifronte del derecho", dado que el tema ya había sido tocado en las reuniones del círculo alentado por este inspirador de grandes corrientes académicas posteriores y reclutador de vocaciones iusfilosóficas. Gioja, a fin de cuentas, fue un gran centro pedagógico socrático de la filosofía del derecho argentina de aquel momento. Claro está que, para ese entonces, no existía la actual categoría de "director de tesis", de manera tal que no podría decirse, en sentido estricto, que Gioja fuese director de la obra que ahora comentamos, pero sí fue un promotor fundamental de la idea, un incentivador crucial del trabajo doctoral de Guibourg.

Como ya lo dijimos, esto fue en buena medida gracias a esas reuniones deliberativas del círculo de Gioja que aumentaron la duda metódica de Guibourg, permitiéndole caer en cuenta —ademásque no estaba ante una falencia exclusiva de la obra kelseniana, sino de todo el positivismo conocido hasta el momento, por lo que terminó incluyendo en su idea doctoral el análisis de las ideas de Olivecrona, Ross y Hart, en torno a la difícil relación entre eficacia y validez.

Vale la pena comentar que, en los ámbitos iusfilosóficos que convergían en la figura de Gioja en los años 60 y 70 del siglo pasado, había un claro predominio del positivismo kelseniano, el cual se vio 


\section{ANDRÉS BOTERO BERNAL}

alimentado por un progresivo interés en la lógica deóntica, interés que estuvo liderado por Alchourrón, Bulygin y Vernengo, y motivado por el nunca autosatisfecho maestro Gioja. Obviamente, este círculo académico estaba en continua controversia con (y no sólo epistemológica sino también política) con los iusnaturalistas tomistas, algunos de los cuales estaban abiertamente a favor de la dictadura y del régimen conservador que en aquel momento se imponía en el país en general y en la UBA en especial. Si se nos permite simplificar, la academia era una forma más de librar una disputa política, en tanto que buena parte de los positivistas de dicho círculo eran defensores de la democracia, aunque entre ellos se diferenciasen por sus orientaciones más particulares, de derecha, de izquierda o de centro, pero democráticos al fin y al cabo. Fue el caso del propio Gioja, un gran defensor de una democracia representativa por partidos políticos, idea política que de alguna manera supo transmitir a sus discípulos, a la par de la curiosidad incesante por la consistencia del pensamiento iusfilosófico.

Igualmente, en esos años, dentro de dicho círculo empezó a formarse una tendencia crítica, provocada y auspiciada por el propio Gioja, capitaneada por jóvenes brillantes más o menos contemporáneos a Guibourg, como Cárcova y Ruiz, por mencionar sólo dos nombres de muchos posibles, quienes empezaron a ejercer cierto grado de rebelión sobre las ideas del positivismo estructuralista y lógicista en boga, con base en autores como Foucault, quien estaba en pleno esplendor.

Y en este círculo liderado por Gioja podemos ver uno de los momentos más altos, a la vez que el nacimiento y la consolidación de las dos corrientes más importantes, de la iusfilosofía positivista argentina: analíticos y críticos. Para sintetizar, Gioja supo cuajar la fama que recorría la filosofía argentina previa, con autores como Cossio con su teoría egológica, para darle bases al positivismo analítico (que tomó una importante fama con los trabajos de Alchourrón, Bulygin y Vernengo) y a la teoría crítica, de la que ya hablamos, todo a pesar de los inconvenientes que la academia del momento tuvo que afrontar: la falta de financiación de espacios de cultivo de la disciplina, de un lado, y los problemas políticos derivados de un régimen dictatorial 
y conservador que logró cooptar en varios momentos la universidad argentina, del otro.

Volviendo sobre la idea de la tesis, esta, una vez aprobada por Gioja, quedó en suspenso por tres motivos fundamentales. El primero por un asunto laboral, ya que como suele suceder en Latinoamérica, los iusfilósofos suelen formarse como tal por fuera de las jornadas laborales, lo que supone mucho menos tiempo que el que tienen nuestros colegas en otras latitudes. El segundo fue por motivos personales: su primer matrimonio. El tercero, más estresante, fue un tema político: se estaba en medio de una dictadura conservadora, con un marcado acento pro-tomista, una dictadura que había logrado cooptar en buena medida los procesos administrativos y académicos de la UBA, por lo cual no había seguridad alguna de la imparcialidad de los evaluadores de la futura tesis.

Sin embargo, algo se avanzó. En 1974 Guibourg empezó el fichado de textos, siguiendo el proceso de recolección de información propio de aquellos años, según la metodología de investigación bibliográfica. Pero fue en el año siguiente, 1975, que algo alentó con vigor la idea de la tesis. En dicho año, Guibourg participó en una mesa redonda organizada por la Asociación de Abogados de Buenos Aires, en la que planteó sus primeros descubrimientos y expuso sus primeras ideas, aquellas que daban vueltas por su mente, siguiendo la gravedad propia de una persona inconforme con lo que admiraba: el positivismo kelseniano. Esta exposición marcó la estructura de lo que sería luego su tesis doctoral.

Mientras tanto, en esos años álgidos, continuamente se convocaban a concursos docentes para ascensos en el escalafón. Debemos recordar que Guibourg fue interino durante 18 años, y si bien se presentaba a estos concursos, sus resultados eran inestables pues generalmente eran anulados y desconocidos por el gobierno universitario y el nacional. Sin embargo, en uno de dichos concursos, logró su ascenso a profesor asociado, pero no a titular, por carecer del título de doctor requerido. Así las cosas, la exigencia del título de doctor terminó siendo un aliciente determinante para lanzarse a la escritura final de la tesis, sumado al sugestivo requerimiento de Vernengo, amigo y maestro de Guibourg, de no darle más vueltas al asunto. Así es que Guibourg, con rigor y disciplina, por fin se dio a 
la tarea de la escritura de la tesis, con unas ideas que cada vez tenía más claras.

La tesis fue defendida, finalmente, en 1986 ya bajo un gobierno democrático y recuperada en buena medida la normalidad académica y administrativa de la UBA. El tribunal fue más que eminente: Alchourrón, Bulygin y Vernengo. Todos reconocidos positivistas analíticos, quienes no dudaron en otorgar "sobresaliente" a la tesis, junto con la recomendación de premio a la mejor tesis de la Facultad de Derecho. Eso sí, a pesar de obtener la más alta nota posible, no logró el "premio Facultad" otorgado a la mejor tesis de cada año.

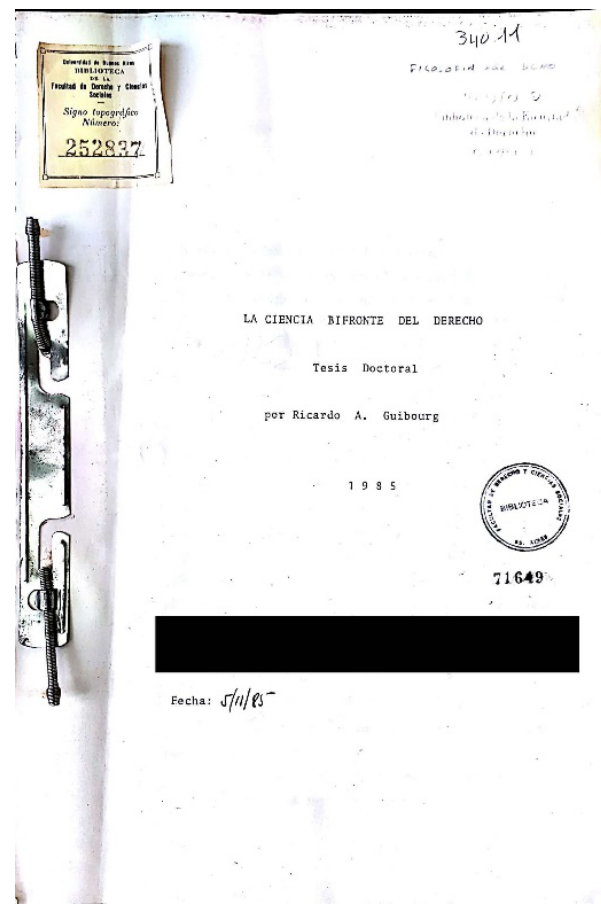

Ilustración 1: Carátula de la tesis doctoral. Imagen propia.

Guibourg publicó ese mismo año su tesis por medio de la editorial Astrea, haciéndole algunos cambios menores: agregó una introducción y algunos subcapítulos de la tesis los volvió capítulos en el libro. Este texto ha sido reimpreso en varias oportunidades, incluso 
en una obra colectiva colombiana. ${ }^{4}$ A pesar de las varias reimpresiones, nunca pasó por la mente de Guibourg una segunda edición que incluyese un cambio importante del contenido, ni siquiera una ampliación de las ideas expuestas en el texto original publicado por Astrea.

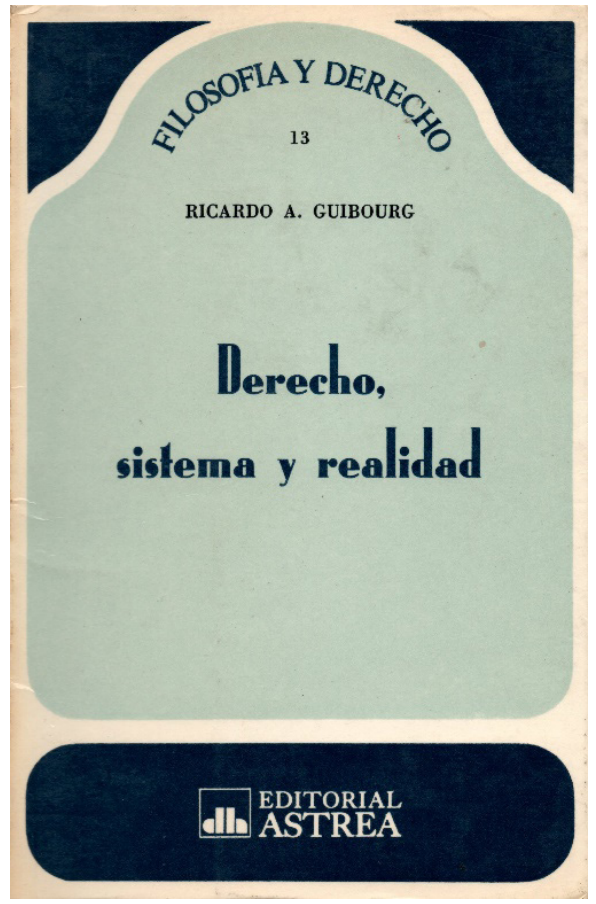

Ilustración 2: Carátula de “Derecho, sistema y realidad”. Imagen propia.

Sin embargo, a criterio de su autor, el libro no tuvo el impacto esperado, aunque apareció citado en los escritos de los amigos, especialmente por los otrora "analíticos españoles". Pero estas citas eran más sobre aspectos circunstanciales de la obra, sobre comentarios aislados de Guibourg en torno a uno que otro autor de los

${ }^{4}$ Guibourg, Ricardo, “Derecho, sistema y realidad”, en Botero, Andrés (coord.), Filosofía del derecho, Medellín, Universidad de Medellín, 2012, pp. 331-373. 


\section{ANDRÉS BOTERO BERNAL}

que analiza en su tesis. Incluso, podríamos decir que el éxito de la obra no estuvo tanto en su conclusión final, a la que aludiremos en el próximo capítulo, sino a las agudas y muy concretas interpretaciones que Guibourg hizo de Kelsen y, en menor medida, de Olivecrona, Ross y Hart. Para señalar un ejemplo, no era de extrañar que muchos iusfilósofos partiesen de esta tesis doctoral para hacer un resumen de las ideas kelsenianas. Resulta que Guibourg, ${ }^{5}$ haciendo alarde de su capacidad sintética, redujo la extensísima obra del austriaco a doce puntos muy específicos, y por ello, la cita a esos puntos, como lo esencial del pensamiento kelseniano, logró un importante eco.

En este sentido, tendríamos que decir, por el momento, que si bien la idea central o conclusiva de la tesis no tuvo la receptividad esperada por parte de su autor en sus colegas, sí tuvieron eco algunos apartados expositivos de la tesis referidos a los autores positivistas allí analizados, a la vez que dicha idea central marcó el rumbo de varias obras posteriores del propio Guibourg (como lo veremos luego).

Pero pasemos a explorar las ideas, el método y las fuentes de la tesis en mención.

\section{LA TESIS DOCTORAL DE 1986}

La tesis doctoral de 1986 tiene un objetivo claro: existen dentro del positivismo dos modelos teóricos, uno que estudia al derecho como norma, y otro como eficacia. Así, una teoría del derecho positivista puede partir desde cualquiera de estas dos corrientes, con utilidad para diversos propósitos, pero el realismo no es útil para explicar la organización interna de las normas, mientras que al normativismo se le escapa la comprensión de las relaciones existentes entre la sociedad y las normas. Entonces, si una teoría positivista busca ofrecer una mirada completa del derecho desde sólo uno de los modelos, cae en contradicción interna al tener que hacerle concesiones al otro; y si pretende analizar al derecho desde los dos puntos de vista al mismo tiempo, cae en contradicción externa por la imposibilidad

5 Guibourg, Ricardo, Derecho, sistema..., cit., pp. 16-19. 


\section{DERECHO, SISTEMA Y REALIDAD...}

de articular de manera plausible esos dos puntos de vista. Así las cosas, el positivismo se hace agua.

Para empezar nuestro análisis, la búsqueda de posibles relaciones entre normativismo-estructuralismo y realismo-funcionalismo ya había sido iniciada con anterioridad por otros iusfilósofos, pero sin llegar a las conclusiones negativas de Guibourg. Por ejemplo, aprovechando el impulso sincrético del sociólogo Talcott Parsons [1902-1979] quien planteó — con alta aceptación en su disciplinala posibilidad de una teoría estructural-funcionalista, ${ }^{6}$ muchos iusfilósofos y iussociólogos, de varias latitudes, intentaron acercar ambas posturas para un mejor conocimiento del fenómeno jurídico. Entre estos intentos podríamos enunciar, a manera de ejemplo, tres:

Primero, de la Estructura a la función, modelo planteado por Bobbio (y que ya se veía en su Teoría general del derecho pero con mayor claridad en Dalla struttura alla funzione ${ }^{7}$ ), quien consideró que el estructuralismo requería abrirse al funcionalismo para entender de mejor forma el fenómeno jurídico.

Dijo Bobbio:

Contrariamente a lo que generalmente se dice, no creo en absoluto que la teoría funcionalista del derecho, tan apreciada por los sociólogos, haya reemplazado a la estructuralista, como si se tratase de dos perspectivas incompatibles. Sucede casi siempre que cuando surge un nuevo enfoque para observar determinado campo de la realidad, se condena apresuradamente el anterior, como si este fuese no solo diferente sino equivocado. Se ignora o se finge ignorar, por efecto del vicio común a toda escuela de tender al exclusivismo, que todo campo de la realidad puede ser considerado desde muchos puntos de vista, y que más bien esta multiplicidad de enfoques ayuda a su mejor comprensión// Esto vale con mayor razón para el derecho, que es una esfera muy compleja de experiencias cuyo conocimiento exige una visión muy global y no sec-

6 Sobre la importancia del planteamiento sincrético de Parsons para la sociología (y para la sociología del derecho), véase Deflem, Mathieu, Sociology oflaw: Visions of a scholarly tradition, Nueva York, Cambridge University Press, 2008, pp. 108-115.

7 Bobbio, Norberto, Dalla struttura alla funzione: Nuovi studi di teoría del diritto, Milano, Edizioni di Comunità, 1977. Igualmente, Bobbio, Norberto, "Hacia una teoría funcional del derecho", en Derecho, Filosofía y Lenguaje: homenaje a Ambrosio L. Gioja, Buenos Aires, Astrea, 1976, pp. 9-30 (s.r.). 


\section{ANDRÉS BOTERO BERNAL}

torial. Los elementos de este universo, que son puestos en evidencia por el análisis estructural, son diferentes de aquellos que pueden ser puestos en evidencia por el análisis funcional. Los dos puntos de vista no solo son perfectamente compatibles sino que se integran mutuamente y de manera siempre útil. ${ }^{8}$

Segundo, el Tridimensionalismo, que ha tenido tres vertientes generales: la primera es la italiana, iniciada por Bobbio, también con su Teoría general del derecho, ${ }^{9}$ lo que le marcó una separación con el pensamiento kelseniano que este autor italiano defendió en su juventud. La segunda es la brasileña, con Reale [1910-2006] a la cabeza, ${ }^{10}$ que es la que mayor difusión ha tenido en muchos países latinoamericanos como Colombia. ${ }^{11} \mathrm{Y}$ la tercera es la argentina, con predominio de Goldschmidt [1910-1987],12 pero que también cuenta en alguna medida con Carlos Cossio y Julio Cueto Rúa [1920-

8 Bobbio, Norberto, "Prólogo a la edición castellana”, en Bobbio, Norberto, Teoría general del derecho, trad. de Eduardo Rozo, Bogotá, Temis, 1987, pp. IX-X. Mayor información en: Amato, Lucas, "Função, estrutura e instituição na análise jurídica", Revista da Faculdade de Direito da Universidade de São Paulo, São Paulo, vol. 112, 2017, pp. 387-408.

9 Bobbio acepta tres dimensiones del derecho, relacionadas entre sí, pero independientes: justicia, validez y eficacia. Bobbio, Norberto, Teoría general..., cit., pp. 26-27, par. 11.

10 Reale, Miguel, Teoría Tridimensional del Derecho (1968), trad. de Ángeles Mateo, Madrid, Tecnos, 1997. Más pedagógico: Reale, Miguel, "El término «Tridimensional» y su contenido", Derecho PUCP: Revista de la Facultad de Derecho, Lima, núm. 50, 1996, pp. 5-9. Robledo Rodríguez, Alejandro, "Metodología jurídica trialista y hermenéutica en la construcción del Derecho", Revista Telemática de Filosofía del Derecho, Madrid, núm. 11, 2007/2008, pp. 269-279.

11 Mantilla, Benigno, "Teoría tridimensional del derecho", Revista da Faculdade de Direito da Universidade de São Paulo, São Paulo, vol. 61, núm. 1, 1966, pp. 69-77.

12 El movimiento, en general, es denominado tridimensionalismo, pero la teoría de este autor en concreto es conocida como trialismo. Explicado en: Goldschmidt, Werner, Introducción filosófica al Derecho, 6a. ed., Buenos Aires, Depalma, 1987. Más claridad pedagógica en: Pezzetta, Silvina, "El marco teórico del trialismo de Werner Goldschmidt y su evolución: algunas ideas sobre los nuevos aportes teóricos", Revista Telemática de Filosofía del Derecho, Madrid, núm. 11, 2007-2008, pp. 245-255. Una nueva formulación del trialismo puede encontrarse en los trabajos de Ciuro, por ejemplo: Ciuro Caldani, Miguel Ángel, Bases iusfilosóficas del Derecho de la Cultura, Rosario, Fundación para las investigaciones jurídicas, 1993, pp. 21-106. 


\section{DERECHO, SISTEMA Y REALIDAD...}

2007]. Sintetizando, el Tridimensionalismo pretende la articulación del iusnaturalismo como el más habilitado para el estudio de los valores en el derecho, del estructuralismo como el más apto para el estudio de la norma y el ordenamiento, y del funcionalismo como el responsable del estudio del derecho como un hecho socio-cultural. Sin embargo, este movimiento, en sus tres vertientes, ha "tropezado con problemas metodológicos y epistemólogicos, basados en la dificultad de ensamblar estas (tres) "dimensiones" entre sí sobre la base del pensamiento tradicional y analítico (de sus cultores)". ${ }^{13}$

Tercero, la Teoría sistémica, ${ }^{14}$ que observa al derecho como un subsistema social cumpliendo funciones (inmunológicas ante la contradicción y el conflicto) que determinan su propia estructura, para lo cual se recurre a la sistémica y las teorías de la complejidad como principal forma de comprender el derecho más allá de la fragmentación impuesta por la Modernidad. Dicho con otras palabras, estructura y función confluyen en el "sistema" jurídico, entendido esto más allá de "ordenamiento normativo".

Ahora bien, la respuesta a las posibles relaciones entre estructura y función sería bien diferente para la tesis de Guibourg, aunque en el próximo capítulo mencionaremos la cercanía de su conclusión con la teoría sistémica, en especial desde la informática jurídica. Vamos directamente a las palabras de Guibourg: "con la interacción de un realismo subyacente y de un formalismo vagamente espasmódico, (mediante la cual) la ciencia del derecho, bifronte como Jano, puede aspirar a cumplir su compromiso con el método empírico y con la

13 El texto entre paréntesis es nuestro. Grün, Ernesto, "La aplicación de la Sistémica y la Cibernética al Derecho", en Botero, Andrés y Estrada, Sergio (comp), Temas de filosofía del derecho, Medellín, Universidad de Medellín, 2003, p. 289. Además: Grün, Ernesto y Botero, Andrés, "Hacia una teoría sistémico-cibernética del Derecho", Vniversitas, Pontificia Universidad Javeriana, Bogotá, núm. 117, julio-diciembre 2008, pp. 41-64.

14 Donde brillan los trabajos de Luhmann, en especial para lo que nos concierne: Luhmann, Niklas, Sistema jurídico y dogmática jurídica (1974), trad. de Ignacio de Otto Pardo, Madrid, Centro de Estudios Constitucionales, 1983. Otra visión sistémico-jurídica, menos sociológica, está presente en: Grün, Ernesto, Una visión sistémica y cibernética del Derecho, Buenos Aires, Abeledo-Perrot, 1995. Una introducción al respecto, en Grün, Ernesto y Botero, Hacia una..., cit., pp. 41-64. 


\section{ANDRÉS BOTERO BERNAL}

práctica jurídica", ${ }^{15}$ pero aun así la ciencia jurídica no podrá —en ningún momento- tener una coherencia interna que le permita decir a los observadores que el buque no tiene desperfectos.

Para llegar a la conclusión anterior, Guibourg señala inicialmente que las fronteras entre funcionalismo y estructuralismo no son del todo claras, puesto que ninguno de ellos dos ha podido prescindir por entero del otro al momento de explicar la complejidad del sistema jurídico. Con miras a demostrar lo anterior, buena parte de la tesis se centra en exponer cómo el normativismo kelseniano se hace agua cuando tiene que incorporar en su teoría la realidad-eficacia, asunto que sucede por ejemplo en tres casos: i) la costumbre (hecho extrasistemático paulatino), pues solo puede ser costumbre válida la que ha sido eficaz en un entorno social; ii) la revolución (hecho extrasistemático brusco), en la medida que sólo la revolución victoriosa (esto es, la eficaz) puede modificar una norma fundamental $\mathrm{y}$, por ende, la constitución válida que fundamenta todo un sistema jurídico; y iii) el desuso (desuetudo) o costumbre negativa (hecho extrasistemático paulatino), ya que si una norma o un ordenamiento no son eficaces ( $a$ ) durante un buen período de tiempo y (b) de forma generalizada, aquella o aquel llegan a perder su validez.

De esta manera, Guibourg, profundizando las impresiones que otros autores previeron, como Cohen, ${ }^{16}$ explica en su tesis que Kelsen tuvo que ceder a planteamientos realistas, como lo fue reconocer que en estos tres casos ya vistos, la eficacia termina por condicionar la validez del ordenamiento o de una norma en concreto. Y es que para Kelsen es necesario, siempre, un mínimo grado de eficacia para poder considerar que un ordenamiento o una norma son válidos, pues de lo contrario operaría la revolución o el desuso: "Una norma jurídica no adquiere solo validez cuando es plenamente efi-

15 Guibourg, Ricardo, Derecho, sistema..., cit., p. 77. En la mitología romana, Jano es el dios de los portales, el de los comienzos y los finales, y es representado con dos caras que representan el pasado y el futuro. En este caso, Guibourg lo usa como alegoría por las dos caras del positivismo jurídico, que parecen independientes entre sí, pero no lo son - o no han podido serlo-, una cara que mira la norma y otra la realidad, pero, a fin de cuentas, caras de un mismo cuerpo o sistema.

16 Cohen, Morris, Reason and Law: studies in juristic philosophy, Glencoe (Illinois), The Free Press, 1950. 
DERECHO, SISTEMA Y REALIDAD...

caz, sino cuando lo es en cierto grado; es decir, cuando es aplicada y acatada en cierta medida". ${ }^{17}$ Igualmente, la costumbre, para ser válida, requiere una acción repetida, general, uniforme, esto es, eficaz. Y ni hablar de la revolución como fundamento de validez de una Constitución: resulta que toda Constitución es válida ya sea porque se hizo conforme a una Constitución anterior o porque es fruto de una revolución que, por ser eficaz, logra imponer una nueva Constitución. Pero incluso cuando fue hecha conforme a una Constitución anterior, cabría preguntarse por la validez de esta última, a lo que se respondería de igual forma: por otra Constitución anterior o por una revolución exitosa. Entonces, tarde que temprano, encontraremos una revolución como el origen directo o indirecto de la Constitución vigente; sin embargo, para poder mantener la pureza de la teoría del derecho, Kelsen propone suponer que la validez de la constitución no depende de un hecho político - como lo es la revoluciónsino de una norma hipotética fundamental, en un primer momento (1934-1960), o de una ficción jurídica (1963), en uno segundo. ${ }^{18}$ En conclusión, en este caso, sólo una revolución eficaz puede lograr cambiar la norma hipotética fundamental o la ficción que sostiene, a su vez, la Constitución vigente. ${ }^{19}$

Justo aquí es menester una reflexión en torno a las fuentes usadas por Guibourg para leer a Kelsen. Él cita en su tesis dos obras kelsenianas. La primera es Teoría general de las normas y del Estado ${ }^{20}$ y la segunda Teoría pura del derecho. ${ }^{21}$ Llama la atención que no si-

17 Kelsen, Hans, Teoría pura del derecho, 14a. ed., trad. de Roberto Vernengo, México, Porrúa, 2005, p. 102.

18 Sobre el cambio de postura de 1963, véase: Ross, Alf, Lógica de las normas (1967), trad. de José S. P. Hierro, Madrid, Tecnos, 1971, pp. 146-147.

19 Al respecto, ver: Guibourg, Ricardo, Derecho, sistema..., cit. La teoría de la "revolución" tuvo eco en muchos países. Por ejemplo, la Corte Suprema de Justicia colombiana (Sentencia de Sala Plena del 28 de noviembre de 1957, magistrado ponente Guillermo Hernández) se declaró incompetente para pronunciarse sobre la convocatoria al plebiscito constitucional de 1957 (que dio lugar al "Frente Nacional"), alegando que dicha ella era fruto de una "revolución" que rompía con el diseño constitucional, por lo cual no podía ser juzgada jurídicamente.

20 Específicamente esta versión: Kelsen, Hans, Teoría general del derecho y del Estado, 2a. ed., trad. de Eduardo García Máynez, México, UNAM, 1958.

21 Kelsen, Hans, Théorie pure du droit, trad. de Ch.Eisenmann, París, Dalloz, 1962. 
ANDRÉS BOTERO BERNAL

gue la versión en sus idiomas originales, inglés y alemán respectivamente, pero usa dos traducciones reconocidas, en especial porque ambas provienen de juristas ampliamente conocedores, in situ, de la escuela kelseniana en Viena. De la Teoría general de las normas y del Estado, ya saben los expertos, que se trató de una obra escrita por Kelsen en 1945 para conciliar su postura académica con el modelo jurídico estadounidense, donde ya estaba afincado, por lo que no tiene de otra que suavizar o matizar varias de las instituciones señaladas en la Teoría pura del derecho, pensada estas últimas más para el derecho continental europeo. ${ }^{22}$

En cuanto la Teoría pura del derecho, como ya se dijo, Guibourg no citó una versión en alemán, porque no domina esta lengua. Pero trabajó con una versión francesa (idioma que maneja muy bien) de la Teoría Pura del Derecho de la segunda edición alemana de 1960, que circulaba con buenos comentarios en el círculo de Gioja, entre otras cosas atendiendo la trayectoria del traductor de dicha versión (Eisenmann) en la escuela kelseniana. Para cuando inició la investigación doctoral, la traducción española de la Reine Rechtslehre de Vernengo (que salió a la luz pública en 1979), no había sido publicada y si bien existía una buena traducción española de Julio Barberis, estaba hecha en mimeógrafo y no fue publicada, al parecer, por no contar con los derechos de traducción. Igualmente, ya circulaban versiones en español y en francés de la Teoría Pura del Derecho, tanto de la primera edición en alemán (1934) como de la segunda (1960), pero la apuesta de Guibourg de quedarse con (la versión francesa de) la segunda de 1960, fue adecuada, dada las diferencias entre ambas ediciones kelsenianas. Sin embargo, para finalizar este párrafo, sí extraña el lector, en especial si está familiarizado con la historia de

22 A manera de ejemplo, en "Teoría general del Derecho y del Estado" (1945), "La paz por medio del derecho" (1944) y en el "Derecho como orden constrictivo" (1949), Kelsen señaló que el derecho, en tanto que controla las conductas coactivamente, promociona la "paz"; mientras que en la obra la "Teoría Pura del Derecho", segunda edición, habló de "seguridad colectiva", para restarle así el impacto axiológico que puede tener la finalidad "paz" y hacerle frente a las críticas recibidas en el sentido de que si la paz es un valor moral, entonces supedita el derecho a la moralidad. La explicación de esta diferencia, así como de otras más en ambas obras, está, entre otras razones, en el público destinatario de las obras. 


\section{DERECHO, SISTEMA Y REALIDAD...}

la filosofía del derecho, la ausencia de una reflexión del tesista que explicase por qué aludir a dos obras (la de 1945 y la de 1960) con contextos de creación tan diferentes, pues si algo está claro, es que entre ellas no hay unidad teórica completa. En fin, esta precisión es importante, dada la confusión que rodea a muchas obras kelsenianas al momento de ser citadas, atendiendo el alto número de ediciones, reediciones y traducciones que existen en el mercado editorial.

Pero Guibourg no se queda con el normativismo kelseniano pues, como ya lo habíamos advertido, quería corroborar que este problema (el de la dificultad de un entronque coherente entre la norma y la realidad, entre el estructuralismo y el funcionalismo) no estaba únicamente presente en la obra kelseniana. De allí su interés de pasar a explorar las tesis de Olivecrona, Ross y Hart, los tres iusfilosófoso positivistas más destacados en las décadas de los cincuenta y sesenta del siglo pasado, junto con Kelsen. Realizándoles la misma pregunta (¿cómo articulan la validez con la eficacia?) llega a conclusiones similares: que todos estos autores terminan por hacerle concesiones al modelo antagónico.

Por ejemplo, frente al realismo de Olivecrona, señala Guibourg:

El realismo extremo permite explicar el derecho como fenómeno social; y hasta puede dar cuenta de las normas de competencia y de la jerarquía de las normas, en cuanto estos elementos formen parte de la actitud general de la población y tengan consecuencias empíricas. Pero la ciencia del derecho (o el estudio del derecho, o la actividad de los juristas, si se quiere) no trata sólo de describir o explicar el hecho jurídico-social: también pretende establecer un sistema de argumentaciones que puedan considerarse intrasistemáticamente válidas y que permiten un diálogo persuasivo entre súbditos y órganos estatales, fundado en reglas de juego conocidas y presumiblemente aceptadas. Y un sistema como el de Olivecrona no facilita esa actividad al reemplazar la sólida pirámide por una duna más o menos volátil. En él cualquier norma que obtenga acatamiento es tomada en cuenta por esta misma causa: el procedimiento regular y la jerarquía o competencia de la autoridad de la que emana no son otra cosa que motivos que pueden coadyuvar a ese acatamiento, pero que no son condiciones necesarias para la calificación que se otorgue a la norma. En estas condiciones el sistema no provee al jurista argumentos para apoyar o discutir la adopción de cierta decisión 


\section{ANDRÉS BOTERO BERNAL}

por una autoridad; en todo caso apenas podría decir algo como: "no me parece que esta norma vaya a gozar de acatamiento general", expresión que puede ser fácilmente contrarrestada con un "esperemos a ver qué pasa. ${ }^{23}$

Sin embargo, este ejercicio de ir a otras posturas diferentes a las kelsenianas genera una duda en lo que atañe a la estrategia narrativa y demostrativa del texto, pues sopesando de manera amplia, podría decirse que un poco más de la mitad de la tesis está en demostrar la falta de coherencia interna en la manera como Kelsen articuló la validez con la eficacia, mientras que el restante se distribuye entre los otros tres autores positivistas: Olivecrona, Ross y Hart. Guibourg opina que, dado el esfuerzo argumentativo y demostrativo en los apartados dedicados a Kelsen, ya no era necesario repetir tal empresa para los casos siguientes tratándose de puntos similares; empero, ese desbalance podría hacerle creer al lector crítico que el análisis de Guibourg, que no fue del mismo calibre dependiendo del autor analizado, muestra una cierta inclinación discriminatoria a favor de Kelsen y una posible falta de rigor, el cual debió ser más parejo al momento de interpretar todos los autores propuestos. A esto último se podría responder que el diámetro de la ojiva depende del espesor de la coraza del buque (Kelsen, para aquel entonces, copaba los espacios académicos mucho más que los otros tres iusfilósofos estudiados), de un lado, y que lo importante no es un tema cuantitativo (el número de páginas y párrafos) sino uno cualitativo (la capacidad de demostración de la idea central del libro en cada uno de los cuatro autores), del otro.

Pasando de esta consideración cuantitativa-espacial (número de páginas dedicadas a un autor u otro), lo que sí es importante resaltar son las conclusiones a las que se llega: la tesis no busca sepultar el positivismo, ni mucho menos ser un llamado de auxilio al iusnaturalismo para que salve a los náufragos. Sólo quería llamar la atención de que el positivismo no era una teoría perfecta (¿acaso la hay?) pues no es posible ser coherente en el normativismo, pero tampoco

23 Guibourg, Ricardo, Derecho, sistema..., cit., p. 71. 


\section{DERECHO, SISTEMA Y REALIDAD...}

en el funcionalismo o realismo, al momento de aludir a las relaciones entre norma y realidad.

Aquí, para explicar mejor estas conclusiones de la tesis, debemos detenernos en varios aspectos. En primer lugar, aclarar que el uso del término "realidad" tanto en el título como en las páginas interiores de la tesis, se refiere a la abstracción normativa de la eficacia. De esta forma, podremos concluir que la realidad a la que se refiere Guibourg en otros textos posteriores, de los que hablaremos en el próximo capítulo, apuntan a otro sentido, más metodológico que normativo. Esto es, que la alusión que se hace en la tesis a la realidad no permite decir, prima facie, que apunte al constructivismo jurídico que sí se vislumbra con claridad en obras como La construcción del pensamiento a la que aludiremos luego.

En segundo lugar, que el interés no era tanto conceptualizar la validez y la eficacia, distinguirlos y aclararlos como diría un analítico, sino de demostrar los defectos internos del positivismo; esto es, denotar que la teoría positivista hacía agua, tenía agujeros. Pero estos agujeros, a pesar de la heroica acción de los seguidores de cada escuela, no podían ser tapados satisfactoriamente, ni mucho menos abriendo agujeros en otras partes del buque para tapar los inicialmente encontrados. Hasta allí llega la obra, con una tímida propuesta de seguir comprendiendo, a pesar de todo, el derecho como fenómeno positivista (sistema de lectura de lo jurídico como norma o como realidad), pero aceptando, humildemente, los límites de las dos principales teorías que se ofertaban en aquel entonces.

En tercer lugar, es lo relativo al título. Como lo dijimos antes, el título de la tesis fue "La ciencia bifronte del derecho" porque el positivismo presenta dos caras, cual Jano. ${ }^{24}$ Una sería la que mira la validez (el normativismo), y otra mira la eficacia de la norma (el funcionalismo o realismo jurídico). Ahora bien, podría pensarse que una mirada corrige a la otra, de manera tal que sumando visiones parciales se tendría una visión general más que aceptable. Pero no; antes bien, estas caras se corroen mutuamente, de manera tal que el normativista no tiene más remedio que aceptar ciertos datos de la realidad que no condicen con su normativismo, por lo que a la pos-

$24 \quad$ Ibidem, p. 77.

Problema. Anuario de Filosofía y Teoría del Derecho $\underline{281}$

Núm. 15, enero-diciembre de 2021, pp. 263-306 
ANDRÉS BOTERO BERNAL

tre terminan por arruinar la coherencia anhelada de su sistema de lectura, y viceversa.

No obstante, el autor, ya al momento de publicar la tesis y ante la sugerencia comercial de la casa editorial, prefirió otro título: "Derecho, sistema y realidad", seguramente por creer que este es más claro y merece menos explicaciones que una tesis titulada de la otra manera. Claro está que tampoco es que el nuevo título le ayude mucho al lector para saber más o menos a dónde va el texto sin haberlo abierto. Pero eso sí, estas tres palabras son justas: se trata de pedirle cuentas a los dos sistemas teóricos dominantes en relación con sus nociones de derecho (entendida como norma) y realidad (entendida como eficacia), sistemas teóricos que terminan corroyéndose mutuamente al no tener un criterio válido de articulación entre los dos conceptos ya vistos.

Y, en cuarto lugar, como correspondía a la época de surgimiento de la idea y de escritura de la tesis, las referencias dadas para demostrar las continuas concesiones que se han hecho ambas caras del positivismo son propias de una teoría estatal del derecho. Sin embargo, en un derecho globalizado no-estatalista (y pensamos, por ejemplo, en la lex mercatoria), donde no es tan fácil advertir jerarquías internas entre normas al estilo de la pirámide kelseniana, y donde predominan más las costumbres y la actividad ordenadora de los jueces y los árbitros que el propio conjunto normativo, ¿podría seguir afirmándose que el normativismo aparece por concesiones o remisiones del propio funcionalismo reinante? Dicho de otra forma, ¿es posible seguir afirmando lo que se concluyó en la tesis, frente al derecho no-estatalista que hoy emerge con fuerza? La pregunta queda abierta.

Así las cosas, ¿qué queda? La obra es tímida en lo que respecta a su propuesta, salvo una invitación a ser teóricos humildes. Digamos, por el momento, que en la iusfilosofía hay tres teorías que pueden ser creídas por sus seguidores (¿fieles?) como perfectas en sí mismas: el normativismo (auspiciado por una interpretación radical neokantiana y una defensa a ultranza de la dualidad norma-realidad por miedo a caer en la falacia naturalista humeana ${ }^{25}$ ), el realismo

25 Finnis, con un buen trabajo de fuentes primarias, sugirió que Hume ha sido 
(por su rechazo fuerte a todo lo que no sea experiencia verificable) $y$, finalmente, el iusnaturalismo (por su apego irrestricto a una naturaleza normativa universal). Pero ninguno sirve por sí sola, porque del iusnaturalismo no sabemos a ciencia cierta qué es lo natural y no ofrece ningún método fiable para acceder a lo objetivo, ${ }^{26}$ del normativismo sabemos que si bien es útil para los operadores jurídicos no tiene un método confiable pues no parte de la experiencia y del realismo sabemos que si bien tiene un método fiable sus conclusiones no son útiles para el normal desarrollo del derecho en sociedad. Podría pensarse que la solución estaría en una teoría intermedia, pero esto no es probable dado que las posturas intermedias se deslizan, por su propia fuerza a los extremos, buscando una coherencia que no se consigue en las zonas grises; sumado a que no es factible la combinación de sistemas teóricos construidos uno en contra del

malinterpretado, incluso por Kelsen, pues el iusnaturalismo, señaló Finnis, no entiende por "naturaleza" el mundo del ser sino un particular mundo del "deber-ser", ya que está claro, incluso desde mucho antes de Hume, que no es posible derivar el "deber-ser" del "ser". Finnis, John, Ley natural y derechos naturales, Trad. Cristóbal Orrego, Buenos Aires, Abeledo Perrot, 2000, pp. 70-82. Este asunto también fue tratado por Ross: "La crítica de Kelsen a las doctrinas del derecho natural es poco satisfactoria o, al menos, es incompleta. Argumenta que las normas morales no pueden ser deducidas de las leyes causales. Pero la "naturaleza" a que se ha referido el jusnaruralismo jamás ha sido la naruraleza de las leyes causales, sino la aspiración o esfuerzo hacia una meta". Ross, Alf, "Nota al libro de Kelsen ¿Qué es la justicia?" (1957)", trad. de Genaro Carrió, en Ross, Alf, El concepto de validez y otros ensayos, trad. de Genaro Carrió y Osvaldo Paschero, Buenos Aires, Centro Editor de América Latina, 1969 , p. 37.

26 Dijo Guibourg: "Desde el iusnaturalismo más tradicional se ha insistido por mucho tiempo - y algunos insisten todavía - en que el positivismo es perverso porque, al olvidar la moral, propone el acatamiento de la voluntad gubernamental, cualquiera sea ella, como la suprema obligación de los seres humanos. A esto llamo yo la leyenda negra... De hecho, se observan numerosos acuerdos de actitud moral entre positivistas y iusnaturalistas, porque la divergencia entre ambos enfoques - conviene enfatizarlo - no es moral sino epistemológica... la diferencia epistemológica consiste en que el iusnaturalista, cualquiera sea la solución que propone, tendrá una fuerte tendencia a sostener que ella es la verdadera solución para el caso, mientras el positivista se limitará a decir que ésa es la que él prefiere y dará las razones que lo llevan a preferirla, sin pretender por eso haber alcanzado alguna clase de verdad". Atienza, Manuel, "Entrevista a Ricardo Guibourg", Doxa, Alicante, núm. 26, 2003, pp. 899 y 904, respectivamente. 
ANDRÉS BOTERO BERNAL

otro. Pero como los extremos no satisfacen a ningún sistema teórico que busca siempre ser lo más puro posible, tenemos que encontrar un modo de convivir con el problema. Eso es lo que Guibourg terminó proponiendo en "Saber Derecho" del que hablaremos en el próximo capítulo. Sin embargo, repetimos, en la tesis doctoral Guibourg sólo llegó a aceptar que cuando se juntan ambas caras, se corroen mutuamente. Y justo esto es lo que se pasa cuando se busca conciliar las posturas de Kelsen, Hart, Olivecrona y Ross en torno a la validez y la eficacia. El desenlace del texto es en alguna medida pesimista, pues termina planteando que el positivismo no tiene salida, aunque nosotros preferimos verlo como una invitación a la humildad crítica. Eso sí, las otras teorías no positivistas tienen menos salida todavía. Por eso Guibourg siguió prefiriendo el positivismo, con todos sus defectos.

\section{PROYECCIÓN DE LA TESIS EN LA OBRA POSTERIOR DE GUIBOURG}

Como lo dijimos al inicio del texto, la tesis doctoral suele marcar un interés académico fuertísimo por parte del autor, que sigue desarrollándose durante su carrera académica. La tesis doctoral de Guibourg está en esta línea, en la medida que no solo el autor se ha negado a hacerle modificaciones a su trabajo de grado, pensando en alguna nueva edición del libro (recordemos que solo se han dado reimpresiones), sino también que fue el fundamento para la escritura de algunas obras posteriores. Podríamos decir, entonces, que Guibourg no ha dejado de creer en las ideas que plasmó en 1986.

Claro está que esta continuidad no la podemos predicar en todas las obras posteriores. Expliquemos esto mejor. Guibourg señaló que sus escritos pueden clasificarse en cinco líneas generales: 1) lógica, 2) teoría general del derecho, 3) teoría general de sistemas, 4) la ética ligada a la ontología y la metodología, y 5) derecho de trabajo, informática jurídica y metodología. ${ }^{27}$ La tesis doctoral, así como la mayoría de las obras que a continuación reseñaremos (específica-

27 Guibourg, Ricardo, “Una concepción analítica del derecho”, en Botero, Andrés (coord.), Filosofía del derecho argentina, Bogotá, Temis, 2008, p. 27. 
mente, Derecho, sistema y realidad, El fenómeno normativo, Pensar en las normas y Análisis de Criterios de Decisión Judicial) hacen parte, según él, de la línea Teoría general del derecho, de manera tal que la continuidad de las ideas doctorales se mantuvo en una línea concreta, en la que nos centraremos a continuación.

Ahora bien, esta continuidad de las ideas de la tesis en la línea de Teoría general derecho nos impiden, por lo menos en el campo iusfilosófico, hablar de un primer y de un segundo Guibourg, como le encanta denominar a los comentaristas a los periodos contradictorios de sus autores favoritos. En este sentido, Guibourg ha sido el mismo. Esto queda claro, si se nos permite ser un poco generales en el análisis, con su obra más reciente: Saber derecho (2013).

Pero para entender mejor la conexión entre la tesis doctoral y el libro de 2013, tenemos que remontarnos a una obra intermedia: $L a$

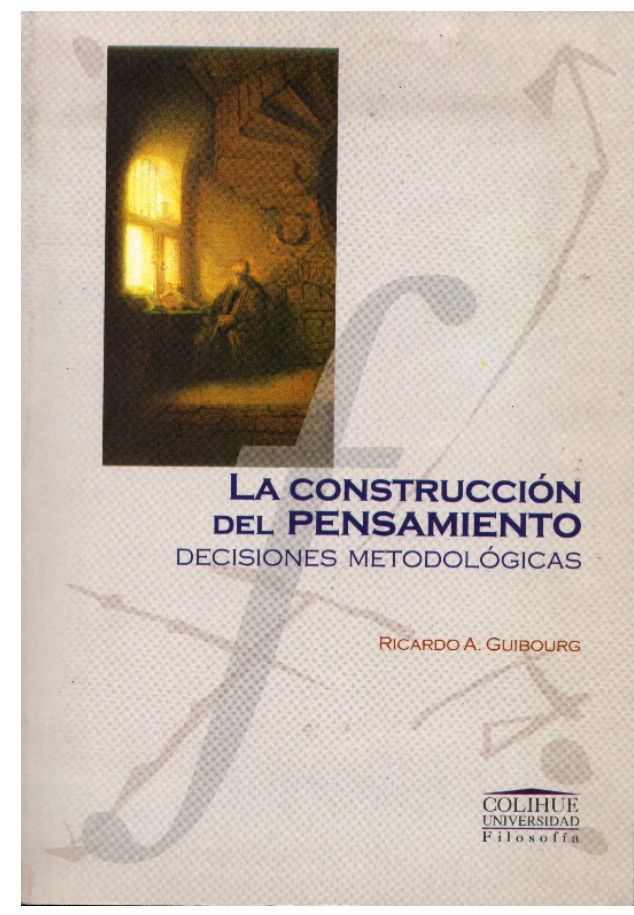

Ilustración 3: Carátula La Construcción del pensamiento, 2004. Imagen propia. 
ANDRÉS BOTERO BERNAL

construcción del pensamiento: decisiones metodológicas ${ }^{28}$ (2004). Este texto no es una obra iusfilosófica en sentido estricto, sino de una apuesta metodológica, como lo indica su subtítulo. Aquí Guibourg toma una posición filosófica-metodológica, posición asumida como una decisión propia, partiendo de la centralidad del método. Aclaremos algo: suele haber dos órdenes posibles de exposición en la filosofía en general y en la iusfilosofía en especial. El primero supone seguir el orden lógico-tradicional de la exposición de las ideas filosóficas que se creen correctas desde un inicio. El segundo es preguntarse por la metodología con la que se observarán las cosas y esta decisión asumida, que es como un orden genético, termina por llevar de lo más cercano a lo más lejano, y por obedecer a un pricipio metodológico asumido como propio se asumen como ciertas las afirmaciones a las que dicho método lleva; orden genético que ya estaba planteado, de forma muy general, en textos anteriores de Guibourg, como Pensar en las normas (1999). ${ }^{29}$ En este caso, esta obra de 2004, con su propuesta metodológica, tiene un claro acento humeano que llevará a Guibourg, como al escocés, a conclusiones pragmático-utilitaristas. Veamos.

Guibourg, en la obra de 2004, asume este orden genético de la siguiente manera (perdón por la simplificación): una persona ve, oye, huele, saborea y toca; esto es, siente impresiones. Estas impresiones sensoriales se asocian con ideas, fruto a su vez de otras impresiones, dando lugar a percepciones e imágenes cada vez más complejas. Pero estas percepciones, o la mayoría de ellas, no dependen de la voluntad de esa persona en tanto que lo que ve no es necesariamente lo que él quiere ver. Por más empeño que ponga en ello, una visión que tenga bajo la claridad de la luz no se pondrá oscura por efecto de su voluntad. Incluso, podrá preguntarle a un vecino si ve claro lo que

28 Guibourg, Ricardo, La construcción del pensamiento. Decisiones metodológicas, Buenos Aires, Colihue, 2004.

29 Dice así: "nada hay más práctico que la teoría, que no es otra cosa que el conjunto de los parámetros que diseñamos para hacer nuestra práctica más eficaz. Y no hay modo de seleccionar o justificar una teoría sin atreverse a adoptar algunas decisiones epistemológicas, que marcan lo que hayamos de entender por práctica eficaz y, por lo tanto, por teoría apropiada para guiarla”. Guibourg, Ricardo, Pensar en las normas, Buenos Aires, Eudeba, 1999, p. 18. 


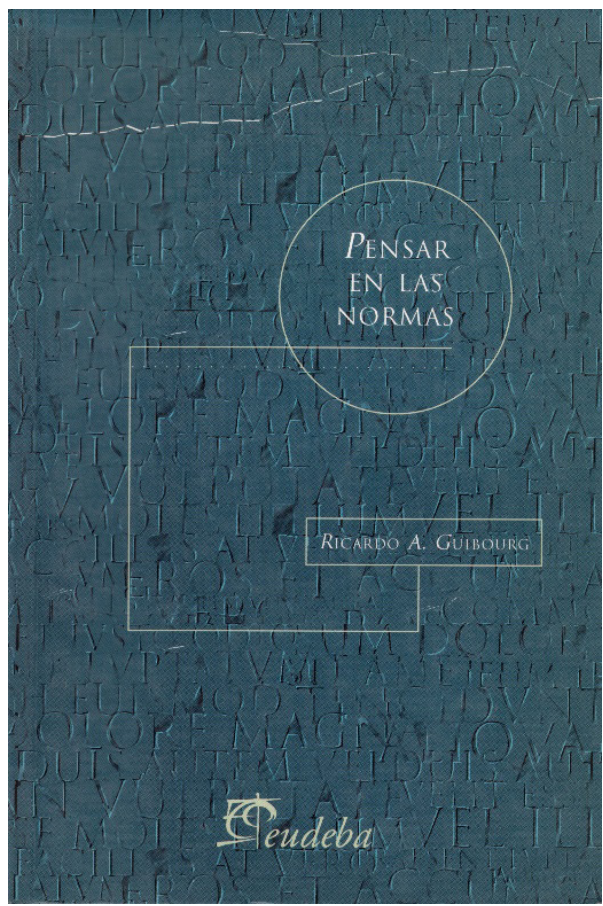

Ilustración 4: Carátula de "Pensar en las normas”. Imagen propia.

esa persona quiere ver oscuro, y la respuesta será -en casi todos los casos de impresiones simples - la misma que esa persona tuvo inicialmente. Así, ante la impotencia de tener como imagen sensorial lo que alguien quiere, imponiéndose la imagen sobre su propia voluntad, surge la idea (que es construida claro está) de realidad. La realidad es una noción compleja creada por nosotros a partir (sin quedarse allí) de lo que sentimos por fuera de nuestra voluntad. ¿Pero eso que la persona llama realidad es algo que existe fuera de él? No lo sabe, no lo puede saber, pero es lo único que tiene y con lo único que puede construir con cierta seguridad. En este sentido, si una persona niega la realidad de la que tiene impresiones, para afirmar que él es lo único que existe, pero que aun así debe seguir viviendo con otros de los que no puede demostrar su existencia, es — pragmáticamente- inútil. El solipsismo es inútil. 
ANDRÉS BOTERO BERNAL

Siguiendo con la narración de las ideas centrales del texto del 2004, luego del concepto de realidad nos inventamos otros conceptos o modelos, para poder hablar (modelar) la realidad que percibimos, y para distinguir según los contextos lo que me viene bien de lo que me viene mal, lo que me gusta de lo que me disgusta. Sin esa capacidad creada de distinguir, la vida no sólo sería monótona; sería inviable.

Dentro de esos modelos encontramos la idea de falsedad y verdad, la cual exige un criterio validador, que en la mente creativa de cada cual puede ser cualquier cosa, pero en la mente de quien desea tener un criterio validador que le sea útil, nada mejor que sea lo único que realmente tiene a su alcance: sus impresiones que son el inicio de lo que llama realidad. Y, para ir un poco más rápidos, a partir de estos conceptos, modelos e ideas, se forma todo lo demás, y como mientras tanto hemos inventado el lenguaje (con sus significantes y significados) se corre el gran riesgo de pensar a la inversa del método inicialmente escogido: que si hay una realidad y es cognoscible en tanto es transportable entre los hombres mediante el lenguaje, cualquier cosa que pueda decirse se vuelve por ello una realidad, incluso aquello de lo que no tengo una impresión sensible. Así aparecen como motores ordenadores de algunos mundos unas ideas metafísicas (en tanto no tenemos experiencia de ellas) tales como Dios, la razón, el hipogrifo, la conciencia, etcétera. Y decimos de algunos mundos porque, al ser solo palabras, cualquier contenido puede asociarse al significante, de manera tal que si bien podría llegarse al consenso de que la conciencia moral rige la conducta, al momento de validar el contenido claro y distinto de lo que es la conciencia moral, nunca llegaríamos a un acuerdo.

¿Qué hacer en este caso? El orden genético. Tomar una decisión metodológica de cómo empezar a construir cada cual su pensamiento. En este sentido, Guibourg opta por creer inicialmente aquello de lo que tiene una impresión; esto es, las impresiones sensibles a las que puede darle el carácter de realidad en tanto que no son impresiones sujetas a su voluntad y que, de alguna manera, pueden ser corroboradas por otro espectador. Este método, el realista, le permite distinguir con algún criterio fiable una cosa de la otra, y allí reside la primera utilidad de su decisión metodológica. 


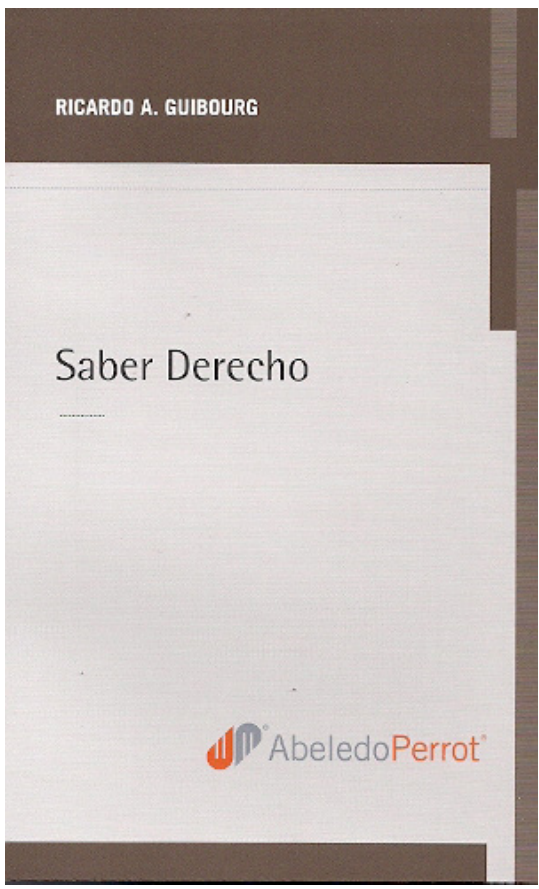

Ilustración 5: Carátula Saber derecho. Imagen propia

Y esta última reflexión nos lleva a Saber derecho ${ }^{30}$ (2013) donde podría decirse metafóricamente que retoma las ideas de su tesis doctoral, pero para darles un apretón de tuercas, a partir de la decisión metodológica asumida en 2004. Obviamente, si comparamos el texto de 1986 con el de 2013, podemos concluir fácilmente que no son textos iguales. Hay diferencias, como el mayor apartado explicativo que hay en Saber derecho. Igualmente, en esta última obra, en vez de plantear que el positivismo de los cuatro autores estudiados se hace agua por no poder ofrecer una teoría satisfactoria en las relaciones entre norma y realidad, entre norma y eficacia, entre estructura y función, en el libro de 2013 asume como campo de análisis un espectro mucho más amplio de las diferentes teorías del derecho y muestra así — con la agudeza del analítico que pasa sus

30 Guibourg, Ricardo, Saber Derecho, Buenos Aires, Abeledo Perrot, 2013. 
ANDRÉS BOTERO BERNAL

arreboles distinguiendo- sus aspectos insatisfactorios. Igualmente, otro punto de notable diferencia entre ambos libros está que, en el último, en el de 2013, asume una posición más propositiva (esto es, menos tímida) aunque igual de humilde ante sus pretensiones como positivista analítico. Veamos.

Guibourg asume en Saber derecho una postura metodológicamente realista, ya explicada en 2004, radicalmente realista si se quiere, para ver hasta dónde se puede llegar sólo partiendo de sus impresiones para saber qué es derecho, y la conclusión (perdón por saltarnos el corpus explicativo) es que si queremos tener un conocimiento jurídico no metafísico, sin concesiones innecesarias a lo que ignoramos, es necesario partir del realismo más absoluto, pero como este no satisface las necesidades argumentativas y pragmáticas de los gobernantes, los jueces, los abogados y los ciudadanos, se impone, por utilidad, la necesidad de un discurso normativista para evitar la arbitrariedad. ${ }^{31}$ Es que el derecho, nos lo dice Guibourg como resultado del orden genérico, es una práctica social, asunto que lo ratifica en un trabajo posterior:

el derecho funciona como una práctica que afecta, favorable o desfavorablemente, a distintos grupos de personas, cada uno de los cuales espera o desea de ellas ciertas prestaciones. Los gobernantes (figura en la que incluyo a los poderes Ejecutivo y Legislativo) desean que sus decisiones se lleven a cabo y que los ciudadanos acaten y cumplan las normas jurídicas por ellos resueltas en una proporción aceptable, que a su vez permita perseguir las conductas disidentes y hasta soportar cierto grado de ineficacia. Los jueces esperan del derecho una guía para sus decisiones, cierto margen de discrecionalidad para satisfacer su conciencia moral, una garantía para su autoridad y un instrumento para hacer cumplir las sentencias. Los ciudadanos en general esperan, al menos, alguna claridad acerca de las conductas que deben ejecutar u omitir para evitarse problemas con la autoridad. ${ }^{32}$

31 Utilidad esta, de evitar la arbitrariedad, que lleva a Guibourg a construir otro texto del que aquí no podemos hacer mayor referencia: Guibourg, Ricardo, Pensar en..., cit., pp. 11-18.

32 Guibourg, Ricardo, Una concepción..., cit., p. 9. 


\section{DERECHO, SISTEMA Y REALIDAD...}

Pero el empirismo puro, el que nos pone de presente que el derecho es una práctica social, no permite argumentar sobre qué es debido o no jurídicamente. El sistema normativo, al no basarse en los hechos, en el puedo causal, sino en el "debe", la pirámide que ofrece el poder para que los agentes sociales se orienten en el qué deben o no hacer atendiendo las consecuencias que se les promete, termina siendo, en el realismo, un charco de lodo, uno que no le permite al ciudadano saber cómo actuar a futuro para evitarse problemas. Para entender qué se debe y no hacer, no puedo partir de la realidad, de las descripciones de conductas acaecidas, sino de una pirámide que le permita al agente establecer estratégicamente su comportamiento.

Expliquemos mejor este asunto. Todos sabemos que no es jurídicamente útil argumentar ante un abogado que algo debe ser así porque suele darse de esa forma. Tampoco es posible convencer a un juez de si alguien actuó o no con dolo — que es una categoría normativa - solo a partir de mis percepciones de la realidad. Los sujetos sociales, como los ciudadanos, requieren y exigen el derecho no tanto para que se les describa una realidad sino para saber cómo deben comportarse o qué deben esperar del otro. Por todo ello, surge como necesidad, fruto de aceptar la realidad de la función del derecho, un normativismo corregido, partiendo del kelseniano, para poder darle funcionalidad social al derecho. Así, el sistema teórico normativista es una necesidad útil derivada del estudio de la realidad perceptible.

Dicho con otras palabras, dado que el estructuralismo ni el funcionalismo dan cuenta por sí solos de lo que es derecho en la sociedad (objetivo central de la obra de 1986), es necesario afirmar, partiendo desde un análisis realista, que el derecho es una práctica social que busca motivar conductas y de allí la importancia de la norma, de un lado, y la pirámide que permite saber qué es norma válida y qué no, del otro. Y si esto es así, se justifica un sistema teórico normativista que analice y clarifique lo que es norma, para saber así qué es o no debido jurídicamente. De esta manera el funcionalismo termina por darle la bienvenida, por la puerta grande si se quiere, al normativismo, a partir de lo que los agentes sociales esperan realmente del derecho, al que conciben como conjunto normativo. 
ANDRÉS BOTERO BERNAL

Sin embargo, este encuentro metodológico entre funcionalismo y estructuralismo no resuelve los problemas de coherencia plena en el campo de las ideas que se le reclaman a ambas teorías. Dicho con una metáfora arquitectónica ampliamente conocida entre positivistas, la pirámide así descubierta está llena de agujeros. ¿Qué hacer entonces? Según la obra de 1986 podríamos decir que la invitación es a fingir que no existen esos agujeros, que el barco no está haciendo agua, pero seguir en el barco en tanto es el mejor posible.

En cambio, en el libro de 2013, no se ignoran dichos agujeros, se asumen. Pero al ser insalvables (no hay teoría que no admita, por lo menos en casos excepcionales, respuestas contrarias a las inicialmente planteadas) se llega a una conclusión similar: las normas positivas tienen un alto grado de convicción - hasta ahora- como motivación normativa entre gobernantes, jueces, abogados y ciudadanos. La norma, como estructura deontológica, sigue teniendo mucha fuerza social, verificable por demás. De tal forma, por una necesidad pragmática fruto del método realista, el funcionalismo no podría renunciar al normativismo, ni viceversa. Así, se asumen los agujeros como males necesarios para la navegación, pero sin creer que Guibourg resolverá, pues no está al alcance de nadie hacerlo, los problemas derivados de la búsqueda de coherencia en las relaciones entre estas dos escuelas o modelos teóricos.

Ahora, en este punto, aunque se nos escape de la intención de nuestro trabajo, Guibourg lanza un grito de alerta: todo parece indicar que, hoy día, en el positivismo ya no es el que está haciendo agua, sino todo el derecho, pero no por la incompleta e inarmónica relación entre normativismo y funcionalismo, sino en virtud de la llegada triunfante de nuevas teorías del derecho con agujeros aún mayores, como el neoconstitucionalismo y el iusnaturalismo. Metafóricamente hablando, un barco puede tener agujeros y seguir navegando, con los correctivos precisos (como un motor que expulse el agua que entra a la embarcación). Pero otra cosa es cuando ya los agujeros son tan grandes que el peso del agua desplazada ya no es igual al peso del barco. ¿Qué pasa entonces? Se hunde. Lo peor es que, siguiendo el ejemplo que hemos puesto, mientras el barco pierde su equilibrio y amenaza de ruina a los marineros (los iusfilósofos) y muchos pasajeros (los agentes sociales) aplauden. 
Es que, en la actualidad, dice Guibourg, el legislador (la gran referencia del positivista) se vuelve, por motivos sociales y políticos, un iusnaturalista más o menos declarado según el contexto. De esta manera, el positivista, en especial el incluyente, considera que debe actuar como iusnaturalista para ser positivista; ${ }^{33}$ de forma tal que los papeles se han invertido (otrora, a inicios del siglo XIX, los iusnaturalistas - fundamentalmente racionalistas - se volvieron positivistas - comentadores del código o exégesis- para poder ser iusnaturalistas). ${ }^{34}$ Es por esto que, actualmente, el positivismo no puede entenderse como una teoría completa sobre la naturaleza normativa del derecho y ningún teórico puede considerarse en un sentido estricto como exclusivamente positivista. De allí que está haciendo carrera el término de "postpositivismo"35 para aludir la

33 Luego del debate Hart-Dworkin, las disputas al interior del positivismo se han centrado en la viabilidad de la denominada tesis de la incorporación, que separa a los positivistas inclusivos de los excluyentes. Un resumen de dicha disputa, en: Moreso, José Juan, “Positivismo jurídico contemporáneo”, en Fabra, Jorge Luis (ed.), Enciclopedia de filosofía y teoría del derecho, México, UNAM, Instituto de Investigaciones Jurídicas, 2015, vol. I, pp. 171-205. Green, Leslie, "Positivism and the Inseparability of Law and Morals", New York University Law Review, vol. 83, 2008, pp. 1035-1058. Dickson, Julie, "Legal Positivism: Contemporary Debates", en Marmor, Andrei (ed.), The Routledge Companion to Philosophy of Law, Nueva York, Routledge, 2012, pp. 48-64.

34 Permítasenos esta corta idea divulgativa. Debemos diferenciar el movimiento de los "comentadores del código civil" francés de 1804, del mito que los iusnaturalistas crearon de ese movimiento y al que le pusieron el nombre de "exégesis", mito que, tristemente, es lo que hoy día circula, cual fantasma, en los pasillos de las facultades de derecho. Lo peor es que el mito terminó por imponerse como mote de todo positivismo, cuando realmente son dos cosas muy diferentes. Rogamos al lector que deje de acusar a alguien de exégeta sin que previamente haya revisado quiénes eran y qué decían aquellos comentadores del código civil a quienes se les ha considerado, anacrónicamente, como los fundadores del movimiento exegético. Al respecto, recomendamos: Botero, Andrés, "Matices a la interpretación tradicional de la exégesis", Revista Jurídicas, Facultad de Derecho de la Universidad de Caldas, Manizales, núm. 2, vol. 9, 2012, pp. 120-135. Hespanha, António Manuel, "Tomando la historia en serio. Los exégetas según ellos mismos", trad. de Andrés Botero, Fórum, Universidad Nacional de Colombia, Medellín, núm. 3, 2012, pp. 13-52; Halperin, Jean-Louis, “Exégesis (escuela)”, trad. de Andrés Botero, Revista de Derecho, Universidad del Norte, Barranquilla, núm. 48, 2017, pp. 263-277.

35 Marquisio, Ricardo, "Tres modelos de postpositivismo jurídico", Revista Ana- 


\section{ANDRÉS BOTERO BERNAL}

superación de los problemas que antes ocupaban a los positivistas, como el de la ciencia bifronte, pero también para evitar malentendidos, basados en muchos mitos y leyendas, de lo que aspira el positivismo como sistema teórico en la actualidad, ya que hoy día muchas preocupaciones sobre el derecho como norma han venido cediendo ante el derecho como argumentación o como principios morales.

Opina Guibourg que el problema de este giro es que la norma escrita, que de por sí es vaga e imprecisa pero que al menos tenía la ventaja de estar al alcance de los ojos del ciudadano, ahora se vuelve más vaga y más imprecisa aún pues al incluirle ideas de las que no tenemos una impresión ni un consenso sobre su contenido, terminan por llevarnos a asumir como reto administrar el derecho sin saber a ciencia cierta qué es y qué no es lo debido. Ya el deber jurídico pierde su relativa autonomía, la que le daba de afirmar que sólo era deber ante el derecho lo que el legislador dijese expresamente, y así al someterse a factores morales y políticos, los teóricos encuentran que no tienen más remedio que acudir, sin saber cómo, a un universo inmaterial donde están las normas-valores universales, cognoscible supuestamente por la recta razón, por la argumentación o por la conciencia moral. Pero esto es, considera Guibourg siguiendo el relativismo axiológico kelseniano, un ejercicio inútil pues por más empeño que le pongamos no son cognoscibles aunque sí valorables (todos tenemos valoraciones, pero de allí que sean las correctas para los demás es imposible por la ausencia de un criterio validador objetivo).

Incluso, agregamos nosotros, esta iusfilosofía de los principios y los valores, suele usar, anacrónicamente, una justificación histórica a lo que hoy en día predican. En el pasado (Antiguo Régimen), las sociedades vivían en un amplísimo pluralismo jurídico, bajo un marco iusnaturalista, y fueron sociedades funcionales. No obstante, conversábamos con Guibourg, esto ha sido mal interpretado, porque si bien es cierto que en el Antiguo Régimen europeo había pluralismo jurídico y jurisdiccional, había muchos aparatos ideológicos (como la religión y la moral cristiana única) que unificaban o amarraban

les de la Facultad de Ciencias Jurídicas y Sociales, UNLP, Buenos Aires, núm. 47, 2017, pp. 864-885. 


\section{DERECHO, SISTEMA Y REALIDAD...}

dicho pluralismo, evitando la distorsión interpretativa, lo que no se da en la actualidad. Además, la exigencia ilustrada de un legislador que concentrase el derecho para darle certeza a los ciudadanos fue justo una respuesta política a esa amplitud del Antiguo Régimen, de manera tal que si leen las fuertes críticas de la Ilustración del siglo XVIII al derecho de la época, queda la duda de qué tan funcional fue, en ese entonces, un derecho tan abierto en sus fuentes interpretativas. Parece que estamos repitiendo un error.

Entonces, siguiendo con las ideas de Guibourg, como nadie demuestra metodológicamente cómo acceder seguramente a ese criterio de principios y valores, ni siquiera sabemos si ese criterio existe (obvio: si no es demostrable la ruta, menos lo es que hay un destino de la misma), se abre espacio para cualquier fantasía retórica, que fácilmente será usada a su favor por las dictaduras del futuro. Podría ser el caso de los derechos humanos, que si bien los demócratas suelen apoyar por pragmatismo político aunque no se pueda afirmar su existencia universal, su vaguedad puede llevar a los jueces constitucionales a creer que se le violan los derechos humanos a un gobernante cuando se le imponen restricciones a su poder, cuando se le imponen pesos-contrapesos, como sería, por dar un caso, el periodo de su mandato (ya tenemos un caso al respecto en Suramérica).

$Y$ los agentes sociales si bien pueden mirar en un principio con buenos ojos la amplitud de fuentes y del lenguaje normativo, con el tiempo podrán cambiar de opinión al darse cuenta de los riesgos que implica proyectar la conducta a futuro sin saber a ciencia cierta las consecuencias que esto les pueda traer. Tal vez venga un reclamo social fuertísimo por volver a tener un derecho más cierto y más claro del que ahora se tiene, lo que nos llevaría a pasar de un extremo (la mítica exégesis) a otro (el neoconstitucionalismo), para volver, cual péndulo, al primero.

Dicho con otras palabras, Guibourg observa preocupado que en el futuro podríamos tener una gran catástrofe en el derecho, pues la actual iusfilosofía está traspasando el poder efectivo del legislador al poder limitado de los jueces, lo que es un problema, dado que la normativa legislada es una sola, mientras que los jueces son miles. Entonces, cuando el derecho le permite a los jueces tener su propio criterio y que este sea obligatorio para las partes, entonces es dere- 
cho lo que cada juez diga o le parezca de buena fe, pero esto puede resultar inadmisible para la parte perjudicada, pues se le está aplicando un criterio normativo que él no podía conocer antes de acaecidos los hechos que se juzgan. Así estamos entrando a una etapa a la que nadie de nosotros sabe cuál es el sistema jurídico que lo rige. Y cuando los ciudadanos reclamen con vehemencia - e incluso con violencia- normas claras para con ellas proyectar su conducta terminarán echándole la culpa de la incertidumbre en la que viven a los jueces, quienes son, dice Guibourg, los menos culpables porque a ellos - a los jueces- les impusieron el actual modelo que hace agua.

Igualmente, los iusfilósofos que hoy día aplauden esta amplitud de fuentes y de nociones de lo que es obligatorio, se lavarán las manos diciendo en su momento que fueron los jueces los culpables por no saber interpretar conforme a los criterios de los otrora felices iusfilósofos, y esto podrá servir de aliciente al poder político para destituir los jueces, quienes terminarán siendo los chivos expiatorios, para nombrar unos que sí tengan un criterio claro de interpretación: el del poder de turno. Dice Guibourg: "Vamos felices a la catástrofe". Por el miedo a la exégesis (que nunca existió, salvo en la mente de los iusnaturalistas), caeremos en una exégesis real. 


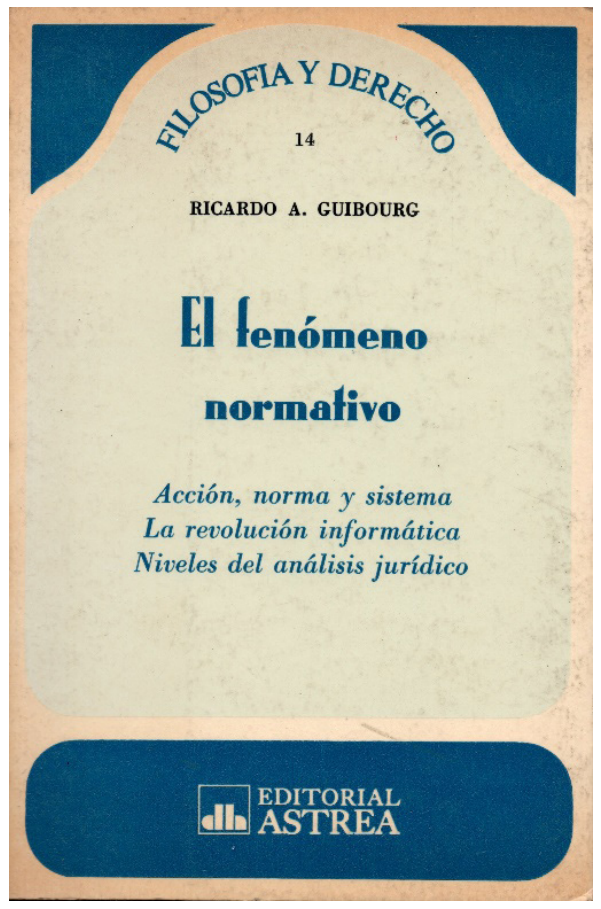

Ilustración 6: Carátula de El fenómeno normativo. Imagen propia.

Así las cosas, ¿qué hacer? Dado que la iusfilosofía en general ha dejado de intentar, por medio del positivismo estructuralista, dar respuesta al problema de la normatividad del derecho, ${ }^{36}$ la ciencia bifronte ya no es una cuestión importante para debatir, salvo entre pocos positivistas. Esto es una de las razones por las cuales Guibourg ha buscado, en otros textos, salirse de ese debate para afrontar algunos más actuales, textos que estarían ubicados tanto en la segunda (Teoría general del derecho) como en la quinta línea de sus obras publicadas. ${ }^{37}$ En esta última línea encontramos su propuesta frente

36 Marquisio, Ricardo, "Teoría del derecho y filosofía moral", Revista de la Facultad de Derecho, Universidad de la República, Montevideo, núm. 38, 2015, pp. 135160.

37 Recordemos que el propio Guibourg clasifica en cinco líneas sus obras: 1) lógica, 2) teoría general del derecho, 3) teoría general de sistemas, 4) la ética li- 
al actual modelo — que califica de solapadamente iusnaturalista-. Fundado en la sistémica y en la informática jurídicas (preocupación tan antigua como la propia tesis doctoral, ${ }^{38}$ con escritos como La justicia y la máquina (1973) ${ }^{39}$ y El fenómeno normativo (1987), entre muchas otras, lo que hace de nuestro autor un pionero en la mate$\mathrm{ria}^{40}$ ), propone que los jueces ofrezcan pautas más o menos objetivas de cómo juzgan a los agentes sociales. ¿Cómo sería? Volviendo

\footnotetext{
Jorge A. Cerdio Herrán - Ricardo A. Guibourg - Miguel Ängel Maza - Liliana Rodríguez Fernández - Sara N.

Silva - María Cristina Solvés - María Teresa Zoppi
}

\title{
ANÁLISIS DE CRITERIOS DE DECISIÓN JUDICIAL
}

EL ARTÍCULO 30 DE LA L.C.T.

\author{
G.A.C. \\ Grupo de Análisis de Criterios
}

2003

Ilustración 7: Carátula de Análisis de criterios de decisión judicial. Imagen propia.

gada a la ontología y la metodología, y 5) derecho de trabajo, informática jurídica y metodología. Cfr. Guibourg, Ricardo, Una concepción..., cit., p. 27.

38 Guibourg, Ricardo, El fenómeno normativo: Acción, norma y sistema. La Revolución informática. Niveles del análisis jurídico, Buenos Aires, Astrea, 1987.

39 Guibourg, Ricardo, “La justicia y la máquina”, Revista La Ley, Buenos Aires, 17 de mayo de 1973.

40 Una síntesis en: Guibourg, Ricardo, "Bases teóricas de la informática jurídica”, Doxa, Alicante, núm. 21-II, 1998, pp. 189-200. 


\section{DERECHO, SISTEMA Y REALIDAD...}

públicos los criterios que los jueces usan, siendo estos, en conjunto, quienes construirían, ora como diagramas de flujo, ${ }^{41}$ ora como un catálogo de situaciones hipotéticas por cada caso juzgable, criterios que estarían a disposición de los ciudadanos y los académicos, para su análisis y crítica. Algo así como imaginar a los jueces como programadores que detallan, con subhipótesis, el programa básico hecho por el legislador, quien queda con la llave maestra para poder así determinar el resultado del programa si lo ve necesario. De esta manera, la estructura básica la aportaría el legislador (en un sentido amplio), pero el detalle de la programación la darían los jueces consensuando entre ellos las diferentes variables de cada caso general establecido por el legislador, programación que siempre estaría a disposición de los operadores jurídicos y en una continua revisión por parte de los jueces colectivamente. Lo interesante es que esto no se quedó en una mera propuesta, concretándose en un estudio piloto debidamente publicado. ${ }^{42}$ Esto sería la primera parte de la entrada de la Inteligencia Artificial al campo del derecho, y una propuesta que le daría cohesión a la sociedad y permitiría la convivencia (aquello que Kelsen llamó la "paz social", aspecto ya comentado en una nota de pie de página) a sus miembros en tanto sería todo público y prestablecido.

En términos de Guibourg esta propuesta:

En primer lugar, alienta al propio juez a analizar con cierta profundidad las razones por las que adopta cierto criterio en lugar de otro, lo que - dentro del marco que haya logrado establecerse- aleja la decisión final de cualquier atisbo de arbitrariedad. En segundo lugar, permite confrontar esas razones con las que otros magistrados, o los abogados en general, invoquen para sustentar criterios diferentes. En tercer lugar, fomenta la seguridad jurídica concebida como previsibilidad de las decisiones, sin abdicar para eso de la capacidad, siempre presente, de cambiar de idea con la misma reflexión y la misma transparencia con las que se adoptara el criterio original. ${ }^{43}$

41 Atienza, Manuel, op. cit., pp. 906 y 907.

42 Cerdio, Jorge et al., Análisis de criterios de decisión judicial. El artículo 30 de la L.C.T., Buenos Aires, Grupo de Análisis de Criterios, 2003 (s.p.) (s.r.).

43 Idem. 
ANDRÉS BOTERO BERNAL

\section{REFLEXIONES FINALES}

Por medio de este escrito dimos un repaso, si se quiere llamarlo así, sobre la tesis doctoral de Ricardo Guibourg. Se empezó señalando la historia (de las ideas) del libro, es decir, el contexto de creación. Igualmente, se dejó en claro que el autor no ha cambiado sus ideas que plasmó en dicha tesis, aunque, como es de esperar, las ha pulido, cosa que queda en claro en sus obras posteriores, en especial Saber derecho donde aprieta aún más las tuercas que ya había apretado en 1986. Claro está, que para poder entender la comunicación que hay entre las obras de 1986 y la de 2013, es necesario comprender la apuesta metodológica del autor expresada en su obra de 2004: $L a$ construcción del pensamiento.

La idea central de la tesis doctoral de 1986 podría reducirse a lo siguiente: que cada una de las dos vertientes del positivismo, el estructuralismo-normativista y el realismo-funcionalista, por más que lo han intentado, no pueden eludir hacerle concesiones a la otra, dada la imposibilidad de abarcar en su sistema teórico la complejidad del derecho. Esta necesidad de hacerle concesiones a la otra corriente se ve con mayor claridad cuando se analizan las relaciones entre validez y eficacia en cuatro autores positivistas, dos normativistas (Kelsen y Hart) y dos realistas (Olivecrona y Ross). El problema mayor radica en que estas concesiones mutuas que se hacen las corrientes terminan por corroerlas, dado que cada concesión es una pérdida de la coherencia interna de cada una de ellas. Pero no hay alternativa. Esto supone, pues, que el positivismo, como conjunto, está haciendo agua, dada la imposibilidad de una teoría integradora de ambas corrientes que sea satisfactoria teóricamente. No obstante, ser positivista —incluso analítico- sigue siendo la mejor alternativa posible:

No afirmo, por cierto, que la escuela analítica tenga respuestas adecuadas ni finales para todos estos problemas. Pero sí estoy seguro de que es el mejor camino para buscar las respuestas que faltan, porque es el modo más práctico de formular las preguntas. Y veo, al mismo tiempo, que otros caminos muy transitados a lo largo de los siglos se pierden a veces en el pensamiento mágico, en la extrapolación salvaje de las prefe- 


\section{DERECHO, SISTEMA Y REALIDAD...}

rencias de algún grupo y en la función de coartada para el ejercicio más descarnado del poder en estado puro. ${ }^{44}$

Finalmente, en este escrito, señalamos que si bien Guibourg sigue compartiendo las ideas de su tesis, bien sabe que ya no hacen parte de los problemas acuciosos de la filosofía del derecho contemporánea. Primero porque con el tiempo podemos prever una disminución significativa en el poder de la iusfilosofía para encauzar los sistemas jurídicos, cada vez más atados a fuerzas políticas y económicas transnacionales. Tal vez, de aceptar esta realidad globalizada, sea la teoría crítica, que consideramos como parte de una de las caras del positivismo, la que más tenga que decir en la actualidad donde la política "en estado puro" y el mal llamado neoliberalismo se imponen arrogantemente sobre la reflexión jurídica. Segundo, porque el positivismo, en general, está rezagado si se le compara con otras teorías recibidas por la iusfilosofía contemporánea con gran alegría, tales como, si seguimos las interesantes provocaciones de Guibourg, el iusnaturalismo camuflado de neoconstitucionalismo y el no-positivismo que aun no se decide qué es.

Y, claro está, la iusfilosofía argentina no es ajena a lo anterior. Si bien la actual iusfilosofía argentina sigue beneficiándose de los altos niveles de desarrollo propios de la época de Gioja (entre otras cosas porque siguen vivos y escribiendo cosas buenas algunos de sus protagonistas), es evidente (o por lo menos así lo creemos) que la iusfilosofía argentina se está envejeciendo y que el relevo generacional que se vislumbra si bien es de calidad no tendrá la misma incidencia que tuvieron sus maestros en el panorama mundial de la disciplina, por muchos motivos, entre ellos las políticas educativas erráticas que no han permitido una evolución progresiva. A esto se suma que la tradición analítica, otrora poderosa, se va desvaneciendo, sin que llegue a desaparecer del todo, ante las nuevas tendencias dominantes: el iusnaturalismo, el neoconstitucionalismo y la teoría crítica.

Pero esto último no es sólo una cuestión argentina: por dar un caso, los analíticos españoles, por conveniencia, han sabido trastocar sus posturas para hacerlas más proclives a los nuevos mercados

44 Guibourg, Ricardo, Una concepción..., cit., p. 6. 


\section{ANDRÉS BOTERO BERNAL}

académicos (mercado editorial, mercado de posgrados, mercado de ideas, mercado de eventos, etcétera).

Ante este panorama, la reflexión sobre una tesis doctoral de 1986 nos lleva a dejar abierta la pregunta por las consecuencias - jurídicas y políticas - de desplazar el análisis normativo del derecho para centrarnos casi exclusivamente en una postura crítica de cómo el derecho es una forma refinada (o una patraña técnica) de dominación, o en una indagación sobre los principios y los valores morales que sólo los mejores podrán vislumbrar para alegría de los menos afortunados (tal cual como lo diría, irónicamente, Guibourg). Y decimos "consecuencias políticas" porque, además de las jurídicas ya señaladas, la propia democracia puede verse seriamente comprometida, dado que esta, piensa Guibourg siguiendo a Kelsen, ${ }^{45}$ solo puede florecer cuando se acepta que todos valoran diferente (relativismo axiológico), lo que es la base de la tolerancia. Cuando se acepta el relativismo no queda otra alternativa para la convivencia que consensuar, entre el mayor número posible de preferencias, lo que será obligatorio jurídicamente. Así, el relativismo y la tolerancia son la base de la democracia. Contrariamente, piensa nuestro autor, si alguien considera que ha encontrado la verdad moral, objetiva y universal de algo, no consensuaría, sino que buscaría imponerla sobre los "menos afortunados" que no la han contemplado, lo cual no es un comportamiento propiamente democrático.

En fin, tal vez la respuesta al dilema de las relaciones entre las escuelas (y no sólo entre estructuralistas y funcionalistas) no debería ser tan problemática, pero esto supondría cambiar el enfoque. Hasta el momento ha sido problemática pues se ha mirado desde lo teórico y desde la coherencia entre los modelos. Guibourg mismo buscó esta coherencia y no la encontró, al darse cuenta que no existe, o por lo menos no al nivel puro o pleno que desean los seguidores de cada cara del positivismo.

En la práctica, podría funcionar algo de mejor manera: concebir la iusfilosofía como un taller, a los conceptos que hemos construido para la comprensión del derecho como una caja de herramientas y al

45 Kelsen, Hans, Esencia y valor de la democracia, trad. de Rafael Luengo y Luis Legaz, Granada, Comares, 2002. 


\section{DERECHO, SISTEMA Y REALIDAD...}

iusfilósofo como un operario quien, según la tarea de turno, pueda tomar la herramienta que requiera, con tal que le sea útil, independientemente del sistema teórico que la propuso y sin cuestionar la utilidad de la herramienta según quien haya sido su creador. Si se requiere un martillo, no se debe buscar un destornillador por más que este último haya sido desarrollado por el mejor de los operarios. Si se requiere atornillar, no se debe pretender clavar por más que esta última acción sea en la que más se sienta competente el operario. La coherencia cedería ante la necesidad de comprender mejor, en el taller de la iusfilosofía (sistema), un fenómeno (realidad) normativo (derecho) específico. Dicho en otros términos, retomamos algo de Guibourg: no sacrifiquemos el barco por garantizar la coherencia de un sistema teórico.

\section{BIBLIOGRAFÍA CITADA}

АмAто, Lucas, "Função, estrutura e instituição na análise jurídica", Revista da Faculdade de Direito da Universidade de São Paulo, São Paulo, vol. 112, 2017.

Atienza, Manuel, "Entrevista a Ricardo Guibourg", Doxa, Alicante, núm. 26, 2003.

Boввio, Norberto, Dalla struttura alla funzione: Nuovi studi di teoría del diritto, Milán, Edizioni di Comunità, 1977.

Bоввіо, Norberto, "Hacia una teoría funcional del derecho", en Derecho, Filosofía y Lenguaje: homenaje a Ambrosio L. Gioja, Buenos Aires, Astrea, 1976.

Bоввіо, Norberto, "Prólogo a la edición castellana”, en BoвBio, Norberto, Teoría general del derecho, Trad. Eduardo Rozo, Bogotá, Temis, 1987.

Botero, Andrés, "Matices a la interpretación tradicional de la exégesis", Revista Jurídicas, Facultad de Derecho de la Universidad de Caldas, Manizales, núm. 2, vol. 9, 2012.

CERDio, Jorge, et. Al, Análisis de criterios de decisión judicial. El artículo 30 de la L.C.T., Buenos Aires, Grupo de Análisis de Criterios, 2003, (s.p.) (s.r.). 


\section{ANDRÉS BOTERO BERNAL}

Ciuro Caldani, Miguel Ángel, Bases iusfilosóficas del Derecho de la Cultura, Rosario, Fundación para las investigaciones jurídicas, 1993.

Cohen, Morris, Reason and Law: Studies in Juristic Philosophy, Glencoe (Illinois), The Free Press, 1950.

Deflem, Mathieu, Sociology of law: Visions of a Scholarly Tradition, Nueva York, Cambridge University Press, 2008.

Dickson, Julie, "Legal Positivism: Contemporary Debates", en MarMOR, Andrei (ed.), The Routledge Companion to Philosophy of Law, New York, Routledge, 2012.

FinNis, John, Ley natural y derechos naturales, trad. de Cristóbal Orrego, Buenos Aires, Abeledo Perrot, 2000.

GoLDSCHMIDT, Werner, Introducción filosófica al Derecho, 6a. ed., Buenos Aires, Depalma, 1987.

Green, Leslie, "Positivism and the Inseparability of Law and Morals", New York University Law Review, vol. 83, 2008.

GrüN, Ernesto y BoTERo, Andrés, "Hacia una teoría sistémico-cibernética del Derecho", Vniversitas, Pontificia Universidad Javeriana, Bogotá, núm. 117, julio-diciembre de 2008.

GRÜN, Ernesto, "La aplicación de la Sistémica y la Cibernética al Derecho", en Botero, Andrés y Estrada, Sergio (comp.), Temas de filosofía del derecho, Medellín, Universidad de Medellín, 2003.

GRÜN, Ernesto, Una visión sistémica y cibernética del Derecho, Buenos Aires, Abeledo-Perrot, 1995.

Guibourg, Ricardo, "Bases teóricas de la informática jurídica”, Doxa, Alicante, núm. 21-II, 1998.

Guibourg, Ricardo, La ciencia bifronte del derecho, Tesis Doctor en Derecho, Buenos Aires, Facultad de Derecho de la Universidad de Buenos Aires.

Guibourg, Ricardo, “La justicia y la máquina”, Revista La Ley, Buenos Aires, 17 de mayo de 1973.

Guibourg, Ricardo, Derecho, sistema y realidad, Buenos Aires, Astrea, 1986. 


\section{DERECHO, SISTEMA Y REALIDAD...}

Guibourg, Ricardo, "Derecho, sistema y realidad", en Botero, Andrés (coord.), Filosofía del derecho, Medellín, Universidad de Medellín, 2012.

GuIBouRG, Ricardo. El fenómeno normativo: Acción, norma y sistema. La Revolución informática. Niveles del análisis jurídico. Buenos Aires: Astrea, 1987.

Guibourg, Ricardo, La construcción del pensamiento. Decisiones metodológicas, Buenos Aires, Colihue, 2004.

Guibourg, Ricardo, Pensar en las normas, Buenos Aires, Eudeba, 1999, 237p. ISBN 9502309820.

Guibourg, Ricardo, Saber Derecho, Buenos Aires, Abeledo Perrot, 2013.

Guibourg, Ricardo, "Una concepción analítica del derecho", en BoTERo, Andrés (coord.), Filosofía del derecho argentina, Bogotá, Temis, 2008.

HALPERIN, Jean-Louis, “Exégesis (escuela)”, trad. de Andrés Botero, Revista de Derecho, Universidad del Norte, Barranquilla, núm. 48, 2017.

Hespanha, António Manuel, "Tomando la historia en serio. Los exégetas según ellos mismos", trad. de Andrés Botero, Fórum, Universidad Nacional de Colombia, Medellín, no. 3, 2012.

KelSEN, Hans, Esencia y valor de la democracia, trad. de Rafael Luengo y Luis Legaz, Granada, Comares, 2002.

Kelsen, Hans, Teoría general del derecho y del Estado, 2a. ed., trad. de Eduardo García Máynez, México, UNAM, 1958.

Kelsen, Hans, Teoría pura del derecho, 14a. ed., trad. de Roberto Vernengo, México, Porrúa, 2005.

Kelsen, Hans, Théorie pure du droit, trad. de Ch. Eisenmann, París, Dalloz, 1962.

Luhmann, Niklas, Sistema jurídico y dogmática jurídica (1974), trad. de Ignacio de Otto Pardo, Madrid, Centro de Estudios Constitucionales, 1983. 
ANDRÉS BOTERO BERNAL

Mantilla, Benigno, "Teoría tridimensional del derecho", Revista da Faculdade de Direito da Universidade de São Paulo, São Paulo, vol. 61, núm. 1, 1966.

MARquisio, Ricardo, "Teoría del derecho y filosofía moral", Revista de la Facultad de Derecho, Universidad de la República, Montevideo, no. 38, 2015.

MARquisio, Ricardo, "Tres modelos de postpositivismo jurídico", Revista Anales de la Facultad de Ciencias Jurídicas y Sociales, UNLP, Buenos Aires, núm. 47, 2017.

Moreso, José Juan, “Positivismo jurídico contemporáneo”, en FABRA, Jorge Luis (ed.), Enciclopedia de filosofía y teoría del derecho, México, Instituto de Investigaciones Jurídicas de la UNAM, 2015, vol. I.

Pezzetta, Silvina, "El marco teórico del trialismo de Werner Goldschmidt y su evolución: algunas ideas sobre los nuevos aportes teóricos", Revista Telemática de Filosofía del Derecho, Madrid, núm. 11, 2007-2008.

REALE, Miguel, "El término «Tridimensional» y su contenido", Derecho PUCP: Revista de la Facultad de Derecho, Lima, núm. 50, 1996.

ReAle, Miguel, Teoría tridimensional del derecho (1968), trad. de Ángeles Mateo, Madrid, Tecnos, 1997.

Robledo Rodríguez, Alejandro, "Metodología jurídica trialista y hermenéutica en la construcción del Derecho", Revista Telemática de Filosofía del Derecho, Madrid, núm. 11, 2007/2008.

Ross, Alf. "Nota al libro de Kelsen ¿Qué es la justicia?” (1957). Trad. Genaro Carrió. En ROSS, Alf, El concepto de validez y otros ensayos, trad. de Genaro Carrió y Osvaldo Paschero, Buenos Aires, Centro editor de América Latina, 1969.

Ross, Alf, Lógica de las normas (1967), trad. de José S. P. Hierro, Madrid, Tecnos, 1971.

SARLO, Oscar, "La gira sudamericana de Hans Kelsen en 1949. El "frente sur" de la teoría pura", Ambiente jurídico, Manizales, núm. 12, 2010. 